\section{RESENHA DO LIVRO CIRCUS MAXIMUS: THE ECONOMIC GAMBLE BEHIND HOSTING THE OLYMPICS AND THE WORLD CUP}

\author{
REVIEW OF THE BOOK "CIRCUS MAXIMUS: THE ECONOMIC GAMBLE BEHIND \\ HOSTING THE OLYMPICS AND THE WORLD CUP”
}

RESEÑA DEL LIBRO "CIRCUS MAXIMUS: THE ECONOMIC GAMBLE BEHIND
HOSTING THE OLYMPICS AND THE WORLD CUP"

Luiz Alberto Pilatti*, Camila Lopes Ferreira*, Bruno Pedroso**, Claudia Tania Picinin*

\author{
Claudia Tania Picinin*
}

\section{Palavras-chave} Economia. Organização. Esportes. Futebol.

Keywords Economics. Organization. Sports. Soccer.

Palabras clave Economía. Organización. Deportes. Fútbol.
Resumo: 0 presente trabalho tem por objetivo resenhar o livro Circus Maximus, de Andrew Zimbalist. Adotou-se o procedimento da resenha crítica. Constata-se, com a leitura do livro, que a realização de megaeventos, principalmente em países em desenvolvimento, em função das exigências impostas pelo Comitê Olímpico Internacional (COI) e pela Federação Internacional das Associações de Futebol (FIFA), produz renda e faturamento muito abaixo dos valores despendidos com a organização dos Jogos Olímpicos e da Copa do Mundo FIFA. Conclui-se que a realização dos megaeventos é um mau negócio para as cidades e países que sediam os eventos.

Abstract: This article is a critical review of Andrew Zimbalist's book Circus Maximus. We found that revenues generated by mega-events are well below the amount spent to organize the Olympic Games and FIFA World Cup, especially in developing countries, due to requirements made by the International Olympic Committee (IOC) and the International Football Association (FIFA). We concluded that mega-events are bad deals for cities and countries that host those events.

Resumen: El presente trabajo tiene como objetivo reseñar el libro Circus Maximus, de Andrew Zimbalist. Se adoptó el procedimiento de la reseña crítica. Se constata con la lectura del libro que la realización de megaeventos, especialmente en los países en vías de desarrollo, debido a las exigencias impuestas por el Comité Olímpico Internacional (COI) y por la Federación Internacional de la Asociaciones de Fútbol (FIFA), producen ingresos y facturación muy por debajo de los valores que se gastan con la organización de los Juegos Olímpicos y la Copa del Mundo de la FIFA. Se concluye que la realización de megaeventos es un mal negocio para las ciudades y países que acogen esos eventos.
* Universidade Tecnológica Federal do Paraná. Curitiba, PR, Brasil. E-mail: clferreira@utfpr.edu.br

${ }^{*}$ Universidade Estadual de Ponta Grossa. Ponta Grossa, PR, Brasil. E-mail: prof.brunopedroso@gmail.com

Recebido em: 30-07-2015 Aprovado em: 18-09-2015 (c) (1) (8) Licence 
O livro Circus Maximus: the economic gamble behind hosting the Olympics and the World Cup é de autoria de Andrew Zimbalist e foi publicado em 2015 pela editora Brookings (Washington, D.C.), ainda sem tradução para o português. $O$ autor é bacharel em Economia pela Universidade de Wisconsin, com mestrado e doutorado na Universidade de Harvard, ambas nos Estados Unidos da América (EUA). Atua como professor de economia do Smith College, em Massachusetts, EUA. É considerado um nome célebre no estudo da economia dos esportes nos EUA.

Circus Maximus é uma superarena romana construída no século VI a.C., com capacidade de público de 250 mil pessoas, para a realização de corridas de bigas e dos Ludi Romani'. O título do livro de Zimbalist faz uma analogia desse local com dois megaeventos contemporâneos, os Jogos Olímpicos e a Copa do Mundo da Federação Internacional das Associações de Futebol (FIFA).

A constatação de que nenhuma cidade queria sediar os Jogos Olímpicos de 1984 é o ponto de partida para Zimbalist discutir a (arriscada) aposta econômica detrás dos megaeventos. A violência e os protestos políticos que marcaram os Jogos Olímpicos realizados na Cidade do México, a morte de 11 atletas israelenses por terroristas em Munique e a dívida de 30 anos tomada pela cidade de Montreal para arcar com um custo 9,2 vezes superior ao inicialmente orçado, marcas maiores, respectivamente, das edições de 1968, 1972 e 1976, eram algumas das razões desse desinteresse.

O desinteresse colocava o Comitê Olímpico Internacional (COI) em uma situação delicada. Sem concorrência, Los Angeles se antecipou e fechou uma negociação favorável com o COI. Pelo acordo, o COI arcaria com eventuais prejuízos e foi facultada a utilização da infraestrutura existente na cidade, que sediara os Jogos Olímpicos de 1932. As condições negociadas, associadas com um marketing inteligente e agressivo, produziram para o Comitê Organizador dos jogos de Los Angeles um superavit de US\$215 milhões.

Os resultados econômicos dos jogos de Los Angeles produziram uma inflexão na atratividade do evento. A disputa pela sede, inexistente em 1984 em virtude do prejuízo econômico ocasionado nos jogos de Montreal em 1976, tornou-se crescentemente tão intensa quanto a luta pelas medalhas em jogo, sentencia Zimbalist. Para as cidades candidatas a sede passou-se a exigir projetos mais abrangentes e complexos. Os custos foram alçados para patamares, até então, inimagináveis. Para ilustrar, Zimbalist cita as edições dos Jogos Olímpicos de verão de 2008, em Pequim, e de inverno de 2014, em Sochi. Os custos dessas edições foram, respectivamente, 40 e 50 bilhões de dólares. Situação análoga acontece com outros megaeventos, como a Copa do Mundo FIFA. Os custos da promoção do evento saltaram da ordem de centenas de milhões de dólares em 1994 para US\$ 5 bilhões na África do Sul, em 2010, e U\$ 15 bilhões em 2014, no Brasil. O custo previsto para a edição de 2022 é de US\$ 200 bilhões.

Para Zimbalist, a história pode estar se repetindo e o cenário de desinteresse existente antes de Los Angeles sendo reconstruído. Os exorbitantes custos impostos, principalmente para países com infraestrutura e serviços públicos deficientes, e a não concretização dos grandiosos benefícios econômicos apregoados estão deixando de seduzir as populações locais. Um dos exemplos citados por Zimbalist é o do Brasil e das manifestações ocorridas antes e durante a Copa do Mundo FIFA, principalmente em função dos investimentos serem majoritariamente 
públicos e distintos das necessidades sociais básicas. Diversos outros exemplos existem e são citados na obra. O que Zimbalist mostra é, em última instância, uma espécie de estelionato em relação às populações "beneficiadas" com as sedes de megaeventos.

Ainda que não seja o foco de Circus Maximus: the economic gamble behind hosting the Olympics and the World Cup², em diferentes passagens do livro são apresentadas as condições que os dirigentes do COI e da FIFA desfrutam e os exorbitantes salários percebidos. Mesmo sem a conotação de denunciar, como ocorreu em Os senhores dos anéis, de Vyv Simon e Andrew Jennings (SIMON; JENNINGS, 1992), ao tratar de temática similar, Circus Maximus coloca em suspeição a alta administração dessas entidades e a integridade dos processos de escolha das futuras sedes.

O processo de sediar um evento é complexo e envolve cifras milionárias. As exigências do $\mathrm{COI}$ e da FIFA são crescentes e, em alguns casos, se sobrepõem à própria legislação dos países que se dispõem a sediar os megaeventos. Diferentemente do que aconteceu em Los Angeles, o custeio é da cidade-sede, enquanto parcela significativa dos valores arrecadados, sempre na casa dos bilhões, é destinada para as entidades administrativas. É inquestionável que, para essas entidades, os megaeventos são um ótimo negócio.

Ainda que existam exceções, o roteiro da preparação e da realização dos megaeventos é similar: o processo de escolha da sede é obscuro e de caráter duvidoso; os benefícios prometidos acabam não se concretizando; acontece desvio do dinheiro público para a realização do evento em detrimento das necessidades prementes das populações envolvidas; acontecem problemas ambientais e, no cotidiano, com as obras de infraestrutura e a realização do evento. Os benefícios e o legado, mesmo que legítimos, acabam se tornando questionáveis. Para Zimbalist, é veemente a comemoração do anúncio do direito de sediar um megaevento. Passados alguns anos, o saldo está invariavelmente naquilo que os economistas chamam de winner's curse ${ }^{3}$.

O quadro que está sendo redesenhado produz um problema real para o $\mathrm{COI}$ e para a FIFA: os protestos populares estão alertando os políticos para o fato de que sediar um megaevento pode ser, do ponto de vista econômico e político, um mau negócio. Menos cidades e países passaram a disputar o direito de sediar os eventos do COI e da FIFA. Em Munique, Alemanha, em novembro de 2013, e em Estocolmo, Suécia, em janeiro de 2014, as populações locais foram às urnas e rejeitaram a candidatura das cidades para sediarem os Jogos de Inverno de 2022. Para evitar outro ciclo de desinteresse como o ocorrido no final da década de 1970, o novo presidente do COI, Thomas Bach, passou grande parte de dezembro de 2013 e janeiro de 2014 tentando convencer possíveis sedes dos benefícios de sediar os Jogos Olímpicos de Verão de 2024. Em fevereiro de 2014, Bach acenou na direção de novas abordagens para 0 processo de escolha das sedes dos eventos do COI.

As questões até aqui colocadas, presentes no capítulo 1 de Circus Maximus, What's Wrong with the Olympics and the World Cup?4, predominantemente com o viés econômico, são aprofundadas nos capítulos seguintes.

O segundo capítulo, Setting the Stage ${ }^{5}$, resgatando aspectos históricos, parte da constatação de que os Jogos Olímpicos modernos têm pouca semelhança com os antigos jogos

\footnotetext{
2 Circus Maximus: a aposta econômica nos bastidores do acolhimento das Olimpíadas e da Copa do Mundo, tradução nossa.

3 Maldição do vencedor, tradução nossa.

4 O que há de errado com as Olimpíadas e a Copa do Mundo?, tradução nossa.

5 Preparando o cenário, tradução nossa.
} 
dos gregos de mais de dois milênios atrás. São apresentadas as origens dos dois megaeventos minudenciados no livro e é descrito o trânsito destes até o presente, com a formatação de Circus Maximus. Também, no capítulo, são apresentados os desafios mercadológicos enfrentados pelo COI e pela FIFA para manterem rentáveis seus preciosos produtos.

No capítulo 3, The Short-Run Economic Impacte, são discutidos os (questionáveis) benefícios de sediar os Jogos Olímpicos e a Copa do Mundo FIFA. De forma irônica, Zimbalist começa o capítulo explicitando o trabalho desenvolvido por dirigentes do COI e da FIFA e de consultores contratados para mostrarem que a realização dos Jogos Olímpicos e da Copa do Mundo FIFA é, desde a invenção da máquina a vapor, uma das melhores ferramentas de desenvolvimento econômico existentes. A realidade pormenorizada é que, quase sempre, o negócio é bom apenas para o COI e a FIFA. Os valores despendidos são muito maiores que a renda e o faturamento gerados.

O capítulo 4, The Long-Run Economic Impact ${ }^{7}$ apresenta um conceito introduzido pelo COI, o conceito de "legado", depois dos Jogos Olímpicos de Sydney, em 2000, para se referir aos presumidos benefícios de longo prazo produzidos com a organização das Olímpiadas. A ampliação da perspectiva é uma espécie de justificação para o aumento dos valores despendidos com a organização do evento nos últimos 30 anos, valores esses que saltaram de milhões para a ordem de dezenas de bilhões de dólares. Com uma ironia ácida, Zimbalist entende que o conceito de "legado" é amplo e abrangente, limitado apenas pela imaginação dos burocratas das entidades administrativas do esporte.

As experiências de Barcelona, com a organização dos Jogos Olímpicos de Verão de 1992, e de Sochi, com os Jogos Olímpicos de Inverno de 2014, são apresentadas no capítulo 5 , Barcelona and Sochỉ. A comparação situa as experiências em extremos opostos no espectro dos benefícios auferidos por sediar os megaeventos. 0 planejamento antecipado, as fontes de financiamento, o potencial cultural e a localização separam drasticamente a experiência das duas cidades e proporcionam uma cautelosa e ilustrativa advertência para potenciais hospedeiros de megaeventos. Barcelona é um caso de sucesso para as cidades que acolhem os Jogos Olímpicos, enquanto Sochi realizou um evento marcado por problemas.

No sexto capítulo, Rio - Brazil and London', são perquiridas as experiências de Londres, com os Jogos de Verão de 2012, do Brasil com a Copa do Mundo FIFA de 2014 e, prospectadas as do Rio de Janeiro, com os Jogos Olímpicos de Verão que acontecerão em 2016. Os contrastes entre as experiências do Rio de Janeiro e do Brasil com as de Londres são manifestados, principalmente, pelas dimensões: grau de desenvolvimento econômico; modelo e metas de planejamento; estilo e eficiência administrativa; e grau de apoio da população local. A ideia, sempre presente, de que os megaeventos podem vir a ser um bom negócio para países desenvolvidos dá o tom das discussões.

O sétimo e último capítulo, Bread or Circuses? ${ }^{10}$, oferece uma avaliação do que funcionou e do que não funcionou nas cidades e nos países que acolheram os jogos, os problemas enfrentados pela FIFA e pelo COI e as mudanças que estão em curso ou devem

60 impacto econômico de curto prazo, tradução nossa.

70 impacto econômico de longo prazo, tradução nossa.

8 Barcelona e Sochi, tradução nossa. 
ser consideradas pelos diferentes atores do complexo processo que é sediar um megaevento. As principais sugestões apresentadas por Zimbalist no capítulo, que considera o monopólio do COI e da FIFA um problema estrutural fundamental, partem justamente dessas entidades administrativas: revezamento entre os continentes para sediar os megaeventos; limitação do número de candidaturas para sediar os megaeventos; autorização da utilização da infraestrutura existente nas cidades que sediarão os eventos; desenvolvimento de estudos de viabilidade congruentes com a realidade; proporcionar aos proponentes compreensão dos riscos reais do ato de sediar um megaevento.

$\mathrm{Na}$ apreciação do livro, considera-se que Circus Maximus é uma leitura necessária para quem estuda o esporte moderno. $O$ tema é relevante e possibilita a compreensão do que realmente é sediar um megaevento. O Brasil sediou a Copa do Mundo FIFA e sediará os Jogos Olímpicos, servindo de exemplo de forma importante nas discussões de Zimbalist. É evidente que a leitura da realidade brasileira, nesse livro que apresenta um olhar de "fora para dentro", não é suficientemente aprofundada. Para uma compreensão ampliada, a leitura de Impactos econômicos de megaeventos esportivos (PRONI; FAUSTINO; SILVA, 2014) permite adentrar nas minúcias do "mau negócio" em que o Brasil se meteu. Proni, Faustino e Silva (2014) utilizam os conceitos de legado e impacto, construídos com diferentes lentes teóricas, para inferir que o legado esportivo perspectivado está constituído de resultados "não esportivos". A lógica da proposição considera a dinâmica do desenvolvimento econômico para promover "cidades globais". As discussões avaliam os pontos positivos e negativos de sediar os megaeventos, os impactos sociais e culturais produzidos pela reengenharia social exigida pelas entidades gestoras do esporte e os possíveis resultados para grupos e pessoas.

Fazendo outra aproximação, é bastante factível dizer que Circus Maximus possibilita entender de forma privilegiada a estrutura do campo esportivo, se observados os parâmetros teóricos de Bourdieu (1983).

A verdade mostrada em Circus Maximus é que, no jogo dos megaeventos, apenas os reais donos da festa (o COI e a FIFA) e uma pequena e privilegiada parcela da economia local (banqueiros e empreiteiros) ganham muito em curto prazo. Todos os outros atores perdem. Em longo prazo, o devir projetado pelo COI e FIFA tem o nome de legado. 0 devir perspectivado por Zimbalist tem o nome de "elefante branco". O teste do tempo, muito rapidamente, está indicando que, infelizmente, Zimbalist está certo. Os megaeventos, para quem sedia, são um mau negócio.

\section{REFERÊNCIAS}

BOURDIEU, Pierre. Questões de sociologia. Rio de Janeiro: Marco Zero, 1983.

PRONI, Marcelo Weishaupt; FAUSTINO, Raphael Brito; SILVA, Leonardo Oliveira da. Impactos econômicos de megaeventos esportivos. Belo Horizonte: Casa da Educação Física, 2014.

SIMON, Vyv; JENNINGS, Andrew. Os senhores dos anéis: poder, dinheiro e drogas nas Olimpíadas Modernas. São Paulo: Best Seller, 1992.

ZIMBALIST, Andrew. Circus maximus: the economic gamble behind hosting the Olympics and the World Cup. Washington, D.C.: Brookings, 2015. 
